去年的 2.705 略微上升了一点, 突破 3 分指日可待。 这个期刊以审稿速度快闻名, 近 5 年的影响因子一 直是稳中有升;

(6) Chinese Medical Journal期刊的影响因子 去年是 1.555 , 今年基本持平为 1.585 ;
（7）沙特阿拉伯主办的 Saudi Medical Journal, 其影响因子去年是 1.055 和今年是 1.195 。

以上是我们对今年 SCI 期刊的简要梳理和分析, 后续我们将进行更深入的解读。请大家持续关注美 捷登官方网站 (www.medjaden.com) 与微信公众号。

\title{
最新JCR报告出炉！抢先知道 中国SCI期刊变化
}

吴敏

武汉美捷登生物科技有限公司

受新冠病毒疫情的影响, 科睿维安 (Clarivate Analytics）稍延迟后终于在美国时间 2020 年 6 月 29 日发布了 2020 年 Journal Citation Reports (JCR, 期 刊引证报告)。随着国家对中国本土期刊发展的重 视以及中国科技期刊卓越行动计划的实施, 在新的 $\mathrm{JCR}$ 发布之际, 我们在这里对国内 SCIE (以下简称 SCI）期刊收录情况和影响因子的变化进行分析报道。

\section{总体分析}

相比去年 213 份中国 SCI 期刊 (可关注美捷登 公众号下载)，今年的中国 SCI 期刊有 241 份 (可关 注美捷登公众号下载)。其中 10 分以上的有 9 份, 相比去年的 5 份, 增加了 4 份。5 分以上有 29 份, 相比去年的 16 份, 增加了 13 份。

\section{二、排名前10的中国SCI期刊}

相较去年, 排名前 10 的中国 SCI 期刊还是发生 了一些改变 (图 1)。其中 Cell Research突破 20, 仍 然领先; Signal Transduction and Targeted Therapy
自去年首个影响因子 5.873 后, 大涨 7 分, 达到 13.49, 进入中国 SCI 期刊第 5 位; Bone Research回 归后的影响因子为 11.508 , 也成为影响排名的一个 重要因素; Science Bulletin从去年的 6.277 涨至今年 的 9.511, 成功挤入前 10 。排名前 10 的中国 SCI 期 刊全部是 JCR Q1 区。

去年排名第 8 的 Cellular \& Molecular Immunology从去年的 8.213 涨至今年的 8.484 , 被挤出前 10。Nano Research不升反降, 从去年的 8.515 降至 今年的 8.183 , 也未能进入前 10 。

\section{三、新增的中国SCI期刊}

新增加的中国 SCI 期刊一共有 29 份, 如表 1 。

\section{四、不再被纳入中国SCI期刊的期刊}

相比去年, Acta Pharmacologica Sinica今年不 再被纳入中国 SCI 期刊, 但仍然被 SCI 收录, 且影 响因子从去年的 4.010 涨至今年的 5.064。其出版国 家变成英国 (图 2)。 


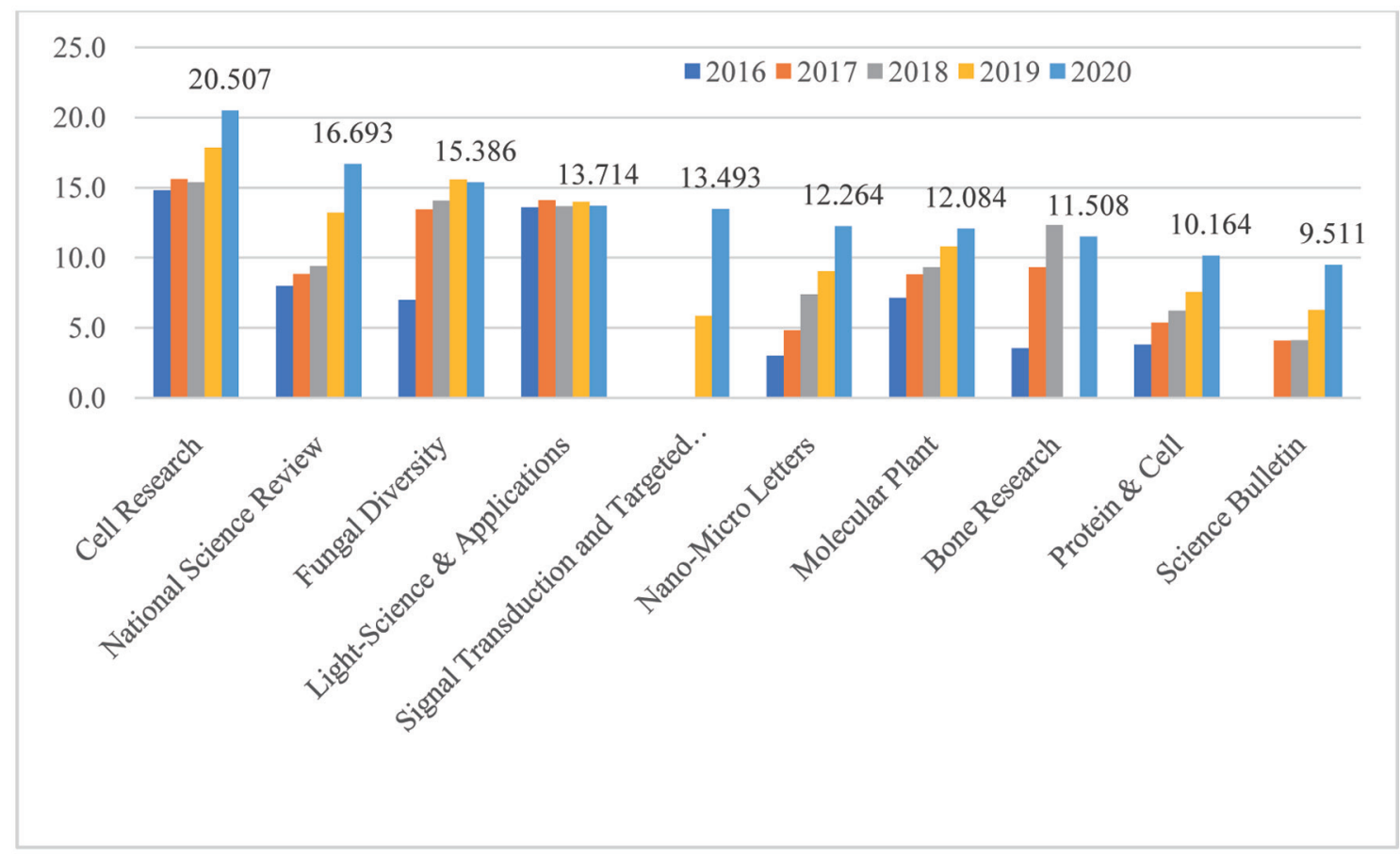

图1 中国SCI期刊Top10的影响因子。

表1. 新收录的中国SCI期刊

\begin{tabular}{llllll}
\hline \multirow{2}{*}{ Rank } & Full Journal Title & $\begin{array}{l}\text { ISSN/ } \\
\text { eISSN }\end{array}$ & $\begin{array}{l}\text { Total } \\
\text { Cites }\end{array}$ & $\begin{array}{l}\text { Journal Im- } \\
\text { pact Factor }\end{array}$ & $\begin{array}{l}\text { Citable } \\
\text { Items }\end{array}$ \\
\hline 8 & Bone Research & $2095-4700$ & 1,679 & 11.508 & 32 \\
11 & Bioactive Materials & $2452-199 X$ & 859 & 8.724 & 39 \\
19 & Green Energy \& Environment & $2096-2797$ & 787 & 6.395 & 46 \\
27 & Journal of Materiomics & $2352-8478$ & 1,209 & 5.797 & 80 \\
31 & Digital Communications and Networks & $2468-5925$ & 492 & 5.382 & 36 \\
36 & IEEE-CAA Journal of Automatica Sinica & $2329-9266$ & 1,604 & 5.129 & 139 \\
41 & Genes \& Diseases & $2352-4820$ & 1,081 & 4.803 & 46 \\
42 & Stroke and Vascular Neurology & $2059-8688$ & 496 & 4.765 & 38 \\
45 & Animal Nutrition & $2405-6383$ & 1,214 & 4.492 & 60 \\
53 & Bio-Design and Manufacturing & $2096-5524$ & 99 & 4.095 & 22 \\
59 & Advances in Climate Change Research & $1674-9278$ & 944 & 3.967 & 20 \\
60 & International Journal of Mining Science and Technology & $2095-2686$ & 2,786 & 3.903 & 115 \\
62 & International Soil and Water Conservation Research & $2095-6339$ & 851 & 3.770 & 39 \\
70 & World Journal of Diabetes & $1948-9358$ & 2,548 & 3.247 & 49 \\
82 & Infectious Diseases of Poverty & $2095-5162$ & 1,685 & 3.067 & 86 \\
86 & Matter and Radiation at Extremes & $2468-2047$ & 330 & 2.931 & 39 \\
91 & Journal of Rock Mechanics and Geotechnical Engineering & $1674-7755$ & 2,323 & 2.829 & 102 \\
115 & Food Science and Human Wellness & $2213-4530$ & 688 & 2.455 & 44 \\
\hline & & & & &
\end{tabular}


表1. 新收录的中国SCI期刊（续表）

\begin{tabular}{llllll}
\hline \multirow{2}{*}{ Rank } & Full Journal Title & $\begin{array}{l}\text { ISSN/ } \\
\text { eISSN }\end{array}$ & $\begin{array}{l}\text { Total } \\
\text { Cites }\end{array}$ & $\begin{array}{l}\text { Journal Im- } \\
\text { pact Factor }\end{array}$ & $\begin{array}{l}\text { Citable } \\
\text { Items }\end{array}$ \\
\hline 118 & Journal of Integrative Medicine-JIM & $2095-4964$ & 754 & 2.446 & 62 \\
123 & Military Medical Research & $2095-7467$ & 386 & 2.325 & 31 \\
124 & Ecosystem Health and Sustainability & $2096-4129$ & 395 & 2.315 & 23 \\
143 & Journal of Palaeogeography-English & $2095-3836$ & 387 & 2.020 & 27 \\
148 & Acta Geologica Sinica-English Edition & $1000-9515$ & 4,558 & 1.973 & 170 \\
152 & Plant Diversity & $2096-2703$ & 260 & 1.864 & 39 \\
153 & World Journal of Gastrointestinal Surgery & $1948-9366$ & 964 & 1.863 & 41 \\
169 & Ecological Processes & $2192-1709$ & 535 & 1.642 & 44 \\
177 & Horticultural Plant Journal & $2095-9885$ & 212 & 1.524 & 31 \\
181 & Communications in Mathematics and Statistics & $2194-6701$ & 175 & 1.500 & 24 \\
193 & Current Medical Science & $2096-5230$ & 206 & 1.273 & 146 \\
\hline
\end{tabular}

ACTA PHARMACOLOGICA SINICA

\begin{tabular}{l} 
ISSN: $1671-4083$ \\
eISSN: $1745-7254$ \\
\hline NATURE PUBLISHING GROUP \\
MACMILLAN BUILDING, 4 CRINAN ST, LONDON N1 9XW, ENGLAND \\
ENGLAND \\
\hline Go to Journal Table of Contents Go to Ulrich's Printable Version
\end{tabular}

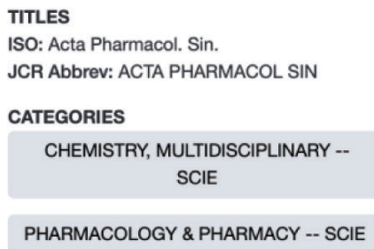

图2 Acta Pharmacologica Sinica基本信息。

以上是我们对今年中国 SCI 期刊的简要梳理和

因子数据可以关注美捷登官方网站 (www.medjaden. 分析，完整的 2019 年和 2020 年中国 SCI 期刊影响 com）与微信公众号查询并下载。

说明: 本文中的中国 SCI 期刊定义为 JCR 报告中地区归类为 China Mainland 的期刊。 